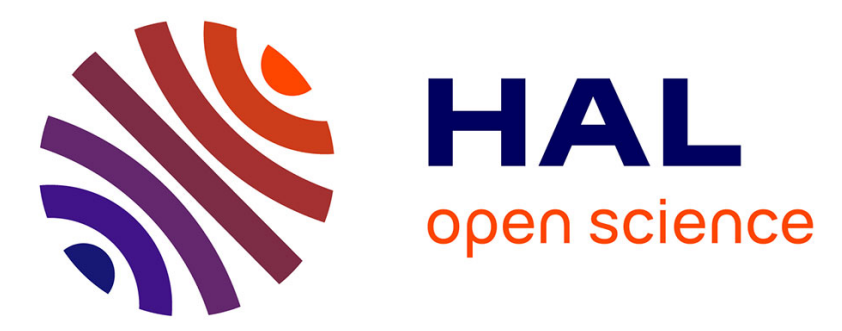

\title{
Network analysis highlights increased generalisation and evenness of plant-pollinator interactions after conservation measures
}

Alessandro Fisogni, François Massol, Natasha de Manincor, Marino Quaranta, Gherardo Bogo, Laura Bortolotti, Marta Galloni

\section{To cite this version:}

Alessandro Fisogni, François Massol, Natasha de Manincor, Marino Quaranta, Gherardo Bogo, et al.. Network analysis highlights increased generalisation and evenness of plant-pollinator interactions after conservation measures. Acta Oecologica, 2021, 110, pp.103689. 10.1016/j.actao.2020.103689 . hal-03383238

\section{HAL Id: hal-03383238 \\ https://hal.science/hal-03383238}

Submitted on 18 Oct 2021

HAL is a multi-disciplinary open access archive for the deposit and dissemination of scientific research documents, whether they are published or not. The documents may come from teaching and research institutions in France or abroad, or from public or private research centers.
L'archive ouverte pluridisciplinaire HAL, est destinée au dépôt et à la diffusion de documents scientifiques de niveau recherche, publiés ou non, émanant des établissements d'enseignement et de recherche français ou étrangers, des laboratoires publics ou privés. 
1 Network analysis highlights increased generalisation and evenness of plant-pollinator interactions

2 after conservation measures

3

4 Alessandro Fisogni ${ }^{1,2^{*}}$, François Massol ${ }^{1}$, Natasha de Manincor ${ }^{1}$, Marino Quaranta ${ }^{3}$, Gherardo Bogo ${ }^{2,3}$, Laura 5 Bortolotti $^{3}$, Marta Galloni ${ }^{2}$

6

7

$8 \quad{ }^{1}$ Univ. Lille, CNRS, UMR 8198 - Evo-Eco-Paleo, F-59000 Lille, France

$9{ }^{2}$ Dipartimento di Scienze Biologiche, Geologiche e Ambientali, Università di Bologna, Via Irnerio 42, 10 40126, Bologna, Italy.

$11{ }^{3}$ CREA - Consiglio per la ricerca in agricoltura e l'analisi dell'economia agraria, Unità di ricerca di apicoltura e bachicoltura, Via di Saliceto 80, 40128, Bologna, Italy.

$15 *$ *Corresponding Author: Alessandro Fisogni

16 Telephone number: (+33) 0320335923

17 e-mail: alessandro.fisogni@univ-lille.fr

e-mail: a.fisogni@gmail.com

Authors' ORCID ID:

21 Alessandro Fisogni: 0000-0001-6179-2767

22 François Massol: 0000-0002-4098-955X

23 Natasha de Manincor: 0000-0001-9696-125X

24 Marino Quaranta: 0000-0003-0082-4555

25 Gherardo Bogo: 0000-0001-7415-2224

26 Laura Bortolotti: 0000-0001-7372-1579

27 Marta Galloni: 0000-0001-5304-7820 


\section{Abstract}

The decline of pollinators may alter the complex system of interactions that they establish with flowering plants, with potential negative consequences on both partners. Within this context, network analysis may be a useful tool to study ecological properties of plant-pollinator interactions and to evaluate the outcomes of conservation actions. Three conservation measures were implemented within the European LIFE+ PP-ICON project to support the local pollinator community of a population of the rare plant Dictamnus albus in a protected area near Bologna, Italy. Artificial nesting sites were installed to support solitary bees, populations of native plants were reinforced to increase foraging resources for pollinators, and colonies of bumblebees reared from wild queens were released in the study area. In this work we evaluate the effects of these conservation actions on plant-pollinator networks over a period of four years, comparing a pre(2011-2012) and a post-conservation (2013-2014) action period. The overall network generalisation increased after the implementation of conservation measures and interactions were more evenly distributed. Module composition significantly changed between the two periods, showing a marked rewiring of interactions. D. albus was a module hub both before and after conservation actions, thus emerging as an important node within its own module. In addition, some plant and pollinator species directly targeted by conservation measures became module connectors, highlighting their increased importance in linking different modules. Finally, the reinforcement of plant and pollinator populations led to increased flower visitation. These results indicate that conservation actions affected species both directly and indirectly and that the network of interactions has potentially increased its robustness and resilience towards possible species loss. This study highlights ways in which network analysis can be used to measure changes in plant-pollinator interactions in response to conservation actions.

Keywords: bees; biodiversity conservation; community structure; modularity; population reinforcement; specialization 
56 The data analyzed during the current study are available in the Zenodo repository, PERSISTENT

57 WEB LINK TO DATASETS: https://doi.org/10.5281/zenodo.2838952

58

59 


\section{Introduction}

An increasing number of studies highlight a generalized decline of insects at a global scale, including important pollinator taxa such as butterflies, wild bees and hoverflies (e.g. Hallmann et al., 2017; Ollerton et al., 2014; Powney et al., 2019; Thomas, 2016). The majority of flowering plants rely on animals for their reproduction (Ollerton et al., 2011). Among them, bees are the most widespread and most important pollinators (Michener, 2007). The loss of bee pollinators and of the complex system of interactions that they establish with the flowering plant species upon which they rely may endanger the maintenance of wild plant communities (Aguilar et al., 2006; Potts et al., 2010; Thomann et al., 2013), and drive down certain ecosystem services, such as agricultural yields of pollinator-dependent crops (Deguines et al., 2014). At the same time, the loss of suitable habitat and foraging resources is among the main causes of bee population decline (Bates et al., 2011; Biesmeijer et al., 2006; Goulson et al., 2008; Hicks et al., 2016).

The study of plant-pollinator networks aims to reveal the structure of the interactions between partners, the mechanisms underlying such a structure, and the role of individual species within the interaction network (Bascompte and Jordano, 2007; Blüthgen, 2010). The complexity of local networks is linked to the dependence of interactions on the composition and space-time turnover of plant and pollinator communities which, in turn, contribute to spatial and temporal differences between local networks (Poisot et al., 2012). Even when species are present in a site at a given time, actual interactions may not occur due to temporal mismatches, to competition or to the low probability of interaction between rare species (Bartomeus et al., 2013; Basilio et al., 2006; Canard et al., 2012; CaraDonna et al., 2017; Fontaine et al., 2008; Olesen et al., 2011).

In addition to their importance for the study of ecological and evolutionary processes, the monitoring of temporal changes of mutualistic interactions and the study of structural network attributes can be important tools for the assessment of conservation projects and management practices (Forup and Memmott, 2005; Kaiser-Bunbury et al., 2010; Tylianakis et al., 2010) and as a criterion of pollination service quality (Elle et al., 2012; Kaiser-Bunbury et al., 2017). Pollination 
network data have already been used to make predictions and inform management decisions (Carvalheiro et al., 2008; Larson et al., 2014), but the use of network analysis to evaluate the effects of practical conservation actions has been reported only in very few cases to date (Burkle and Alarcón, 2011; Forup et al., 2008; Forup and Memmott, 2005). Recently, Kaiser-Bunbury and Blüthgen (2015) proposed a framework of the most suitable quantitative network metrics to evaluate the outcomes of conservation actions in plant-pollinator networks. These metrics include both diversity and distribution measures. Interaction evenness allows evaluating the homogeneity of links in a network, while measures of specialization-generalisation highlight the level of species dependency on few species (Blüthgen et al., 2006). Modularity measures how species are organized into modules, i.e. link-dense regions in which species interact more strongly with each other than with species in other modules (Olesen et al., 2007). Such metrics can help indirectly to understand functional robustness and vulnerability of networks, reveal preferential ecological interactions between species, and potentially assess the effectiveness or recommend further development of conservation measures. From a conservation perspective, priority should be given to species with complementary functions, while functionally redundant species could be of lower importance (Blüthgen and Klein, 2011). Nevertheless, restored ecosystems can display increased diversity of pollinator species, higher reproductive performance of common plants, and higher network generalization, indicating increased functional redundancy (Kaiser-Bunbury et al., 2017). In contrast to predictions based on simulation models that do not account for changes in the efficacy of particular plant-pollinator relationships, Brosi and Briggs (2013) empirically demonstrated that even a single pollinator species loss may negatively affect network robustness, reducing plant reproductive success. The fragility of plant-pollinator networks to species loss can be estimated by studying network organization and its effects on assemblage robustness, i.e. to what extent the structure and stability of interactions deviate from a pre-existing situation or how many secondary extinctions occur as a result of perturbations (Astegiano et al., 2015; Dunne et al., 2002).

Here we analyze the effects of conservation actions on plant-pollinator networks in a Natural Park. 
Conservation actions were performed within the LIFE+ PP-ICON project (www.pp-icon.eu), and were primarily motivated by evidence of pollination limitation on a focal plant species, Dictamnus albus L. (Fisogni et al., 2016). Three main actions were implemented throughout the duration of the project (four years) to support the pollinator community of D. albus. First, artificial nesting sites were installed to facilitate colonization by solitary bees (e.g. Osmia spp., Megachile spp., Xylocopa spp.); second, bumblebee (Bombus terrestris) colonies - obtained from previous captures in the study area and subsequent rearing of wild queens in the laboratory - were released in the area; finally, populations of native plant species that produce pollen and nectar (hereafter: bee plants) were reinforced to increase the availability of foraging resources throughout the pollinators' life cycle (detailed methodology may be found in the subsection 2.2 of this article and in Bortolotti et al., 2016). Our objective is to evaluate the effects of these conservation measures on mutualistic interactions between flowering plants and wild bees. We focus on a wild population of $D$. albus and its pollinators, which include only bees (Fisogni et al., 2011, 2016), and on the flowering plants found in its surrounding area. The aims of this study are to evaluate i) modifications of network structural properties after the implementation of the conservation actions, ii) the effect of the conservation actions on plant and pollinator species roles within the networks, and iii) the effect of plant species abundance and phenology on pollinator visits.

\section{Materials and methods}

\subsection{Study site and focal species}

This study was performed within a Natura 2000 site (SCI-SPA IT4050001) in the Regional Park "Parco dei Gessi Bolognesi e Calanchi dell'Abbadessa", on the hills nearby the city of Bologna, Italy $\left(44^{\circ} 25^{\prime} 11.734^{\prime \prime} \mathrm{N}-11^{\circ} 23^{\prime} 56.029^{\prime \prime} \mathrm{E} ; 167\right.$ - $200 \mathrm{~m}$ a.s.1.). The site presents a mosaic vegetation growing on clay soil, composed of xeric woods and shrubs dominated by downy oak (Quercus pubescens Willd.) and manna ash (Fraxinus ornus L.) surrounded by grasslands, resulting from abandoned coppice and pastures. 
The focal species, Dictamnus albus, is a perennial herb that flowers from the end of April to midMay and grows at the edge between woods and grasslands and within wood clearings. Fertile racemes bear several showy white and purple flowers; anthers become dehiscent prior to stigma receptivity and flowers show a gender-biased nectar production towards the late female-phase (Fisogni et al., 2011). Medium- to large-sized bees (Hymenoptera: Apoidea: Anthophila) are its most important pollinators, and include both social (e.g., Bombus spp.) and solitary (e.g., Habropoda tarsata, Xylocopa violacea, Osmia spp.) bees; smaller bees (e.g. Halictidae, Ceratina spp.) only rarely act as effective pollinators (Fisogni et al., 2016). D. albus is listed as "LeastConcern" in the European Red List (Chappuis, 2014), but it is included as "Vulnerable" in several national Red Lists and is locally protected throughout Europe (Schnittler and Günther, 1999).

\subsection{Conservation actions}

Three main conservation actions were implemented in the study area to favor both plants and their bee pollinators. 1) Artificial nests for pollinators were provided throughout the development of the study. Nest occupancy was impaired in 2011 because of colonization by ants. Solitary bees started nesting in 2012, and emerged in 2013. A high number of cavities were also occupied in 2013 and 2014, and further more complex artificial nesting sites (i.e. bee hotels) were added in 2014 and readily occupied by a variety of solitary bees (e.g. Anthidium manicatum, Osmia spp., Megachile spp., Xylocopa violacea). 2) Populations of seventeen native plant species that are visited by local pollinators were planted in the study area. Plants were chosen to have a flowering out of phase with that of the focal species D. albus, to avoid competition for pollinator visitation. The majority of plants successfully established few to several individuals in 2013 and 2014. 3) A total of fourteen colonies of the buff-tailed bumblebee (B. terrestris) were reared in the laboratory starting from wild queens captured in the study area, and were released in the project area in 2013 and 2014. More details on methodology, materials and outcomes of these actions can be found in Bortolotti et al. (2016). 


\subsection{Permanent transects in the flowering community}

To study the links between plants and pollinators, we considered a $200 \mathrm{~m}$ long $\times 2 \mathrm{~m}$ wide permanent transect, representative of the project area. We chose a single transect because of the small area concerned by the conservation actions and because of the restricted distribution of $D$. albus populations. Moreover, the peculiar geomorphology of the Regional Park limited additional transects, because of widespread ravines and woodlands not favorable to the establishment of $D$. albus populations. The transect was designed to cover the largest diversity of flowering plants in the study site throughout the season. In addition, it included the majority of $D$. albus plants during their peak of blooming and encompassed all the bee plants that were planted during the conservation actions. We performed monthly pollinator surveys from March to September (7 surveys) for four consecutive years (from 2011 to $2014 ; 28$ surveys overall). The transect was walked by one experienced operator at an even pace four times on survey day at fixed hours ( 9 and 12 AM, 3 and 6 PM), to cover most of the bee foraging activity period. During each transect, all individual bees that visited open flowers to collect pollen or nectar were recorded, as well as the plant species visited. These insects were accounted pollinators for this study purposes, regardless of their pollination efficiency. Where possible, all bees were sampled by hand net and individually stored in vials containing paper-tissues soaked with ethyl acetate and brought to the laboratory for taxonomic determination. Some individuals left flowers before we could capture them $(n=41)$ : in this case the lowest taxonomic level recognizable by field observations (family or genus) was noted and the interaction was recorded.

\subsection{Flower abundance}

Immediately after finishing sampling along the permanent transect, the same operator walked the transect a second time to estimate the abundance of the flowering plants encountered therein. For this estimation, we considered floral units such as single flowers, flower heads, spikes and umbels 
190

(sensu Gibson et al., 2006). Based on floral units, flowering species were ranked qualitatively in classes of abundance using the following categories: 1 - low abundance (solitary or sporadic floral units); 2 - medium abundance (sparse floral units or small groups); 3 - high abundance (up to half of the floral units in the area belonging to the species); and 4 - dominant species (more than half of the floral units in the area belonging to the species).

\subsection{Data analysis}

Since conservation measures were performed gradually throughout the first two years of the LIFE+ PP-ICON project and became established starting from the third year of the study (Bortolotti et al., 2016), we assessed the effects of such measures by dividing the four years of data in two periods: a pre-conservation action period $(2011-2012)$, and a post-conservation action period $(2013-2014)$. We also aggregated two years in each period to reduce the inter-annual variability associated with natural fluctuations and to have sufficiently large data sets to allow all the analyses. We evaluated plant and insect species turnover by calculating the presence/absence-based Sørensen similarity index $(S)$. All analyses were performed with R ver. 3.3.2 (R Core Team, 2016), using the following R packages: igraph (Csardi and Nepusz, 2006), bipartite (Dormann et al., 2008), lme4 (Bates et al., 2015), alluvial (Bojanowski and Edwards, 2016), and vegan (Oksanen et al., 2019).

\subsubsection{Network analyses}

Since monthly networks were small and the aim of this study was to compare the total pre- and post-treatment conditions, we aggregated observations of all months in each year to obtain a more exhaustive representation of the plant-pollinator interactions. We then built two two-year pollinatorby-plant visit matrices (V) corresponding to the pre- and post-conservation action networks. In each $\mathbf{V}$ matrix, the value in the cell at row 'a' and column ' $p$ ' represents the number of visits of pollinator species ' $a$ ' to plant species ' $p$ ' in that observation period. We also analyzed pollinator-by-plant incidence matrices (A) in which the value of each cell is 0 or 1 and represents an absent or recorded 
interaction, respectively $\left(a_{i j}=1\right.$ when $\left.v_{i j}>0\right)$. Plant and insect phenologies (i.e. temporal changes in presence/absence) were considered in further analyses (PERmutational Multivariate ANalysis Of VAriance between species role and phenology, see below) to account for effects related to seasonal species occurrence.

We calculated the connectance $(C$, the proportion of observed interactions over all possible interactions) for both the pre- and post-conservation action networks. At the network level, we calculated the specialization index $\left(H_{2}{ }^{\prime}\right)$ and the associated interaction evenness $\left(E_{2}\right) . H_{2}{ }^{\prime}$ is a measure of the complementarity of interactions within a given network, and it ranges between 0 (extreme generalisation of species in the networks) and 1 (extreme specialization; Blüthgen et al. 2006). Interaction evenness evaluates the homogeneity of relative interaction frequencies across all links in the network (Blüthgen et al., 2008). Higher evenness values reflect a more uniform distribution of interactions among the species. We also calculated the specialization index $\left(d^{\prime}\right)$ at the species level. $d^{\prime}$ ranges between 0 and 1, with high values indicating specialization (Blüthgen, 2010). Both $H_{2}{ }^{\prime}$ and $d^{\prime}$ are not affected much by variation in sampling effort and by the incompleteness of sampled plant-pollinator interactions (Blüthgen et al., 2007).

To test for significant differences between pre- and post-conservation action metrics, the difference between the respective indices $\left(\Delta_{\text {observed }}\right)$ was compared with that predicted by permutation-based null models $\left(\Delta_{\text {permutation }}\right)$. To construct the null model, we re-sampled visits involving species pairs (insect and plant) after pooling all observed visits (from both pre- and post-conservation action periods) together. Re-sampling kept the number of visits in each period constant, but randomly shuffled the period in which each of the visit "happened" in the permuted dataset. We performed 10,000 permutations and compared the $\Delta_{\text {observed }}$ with the distribution of $\Delta_{\text {permutation }}$ to look for significant differences (i.e. differences between pre- and post-conservation metrics that would not have been predicted if visits had occurred randomly in one of the two periods).

We calculated network modularity $(M)$ and module composition using the 'cluster leading eigenvector' algorithm (Newman, 2006). To evaluate the importance of modularity in a given 
period we compared the modularity obtained for the A matrices with that obtained using a randomized matrix with given degrees for presence/absence interaction tables (method 'curveball'; Strona et al., 2014) with 10,000 permutations. We compared modularity values obtained in the preand post-conservation action periods using the same permutation-based null model as described above for the other network metrics. To evaluate the similarity in module composition before and after conservation measures, we calculated the normalized mutual information index (NMI, Danon et al., 2005) of the modular structure of interaction networks for the two periods restricted to species occurring in both periods, and compared it with values obtained from randomized tables that conserved the species degree distribution of the observed networks (Astegiano et al., 2017). We used alluvial diagrams to show the species rearrangement among modules in the two periods considered.

To define the role of each species with respect to network modularity, we calculated their withinmodule degree (z-score) and among-module connectivity (c-score) values (Guimerà and Amaral, 2005) based on the results of the aforementioned modularity analysis with the 'cluster leading eigenvector' algorithm. According to Olesen et al. (2007), peripheral species (i.e. specialists) have $z$ $257 \leq 2.5$ and $c \leq 0.62$; module hubs (i.e. highly connected species within their own module) have $\mathrm{z}>$ 2582.5 and $\mathrm{c} \leq 0.62$; connectors (i.e. species linking several modules) have $\mathrm{z} \leq 2.5$ and $\mathrm{c}>0.62$; network hubs (i.e. super generalists, acting as both connectors and module hubs) have $\mathrm{z}>2.5$ and $\mathrm{c}$ $>$ 0.62. We performed a PERMANOVA to test whether the values of the $\mathrm{c}-\mathrm{z}$ scores obtained for both plants and insects, before and after the conservation actions, were affected by phenology (i.e. the number of months in which a flowering plant or an insect species were observed).

\subsubsection{Determinants of flower visitation}

To assess the effects of flowering abundance, flowering phenology and conservation actions on the abundance of insect flower-visits to the overall flowering community, we summed the total number of visits by all bee species on all the plant species belonging to a given abundance class. The total 
flower visits were analyzed with Generalized Linear Mixed Models (GLMMs) fit by maximum likelihood with Laplace approximation and a negative binomial distribution with log-link (Bolker et al., 2008). We used the plant species abundance rank (from 1 to 4), the plant phenology (i.e. the number of months in which a given plant species was in bloom; $\min =1$, $\max =7$ ), and the occurrence of conservation actions $(1=$ pre-conservation action period, $2=$ post-conservation action period) as explanatory variables. Plant abundance and phenology were considered in the models as categorical variables in order to allow for non-linear relationships. We included 'plant species' as a random factor in all models to account for inter-specific variability. We started by computing the most complex model (full model with all of the abovementioned explanatory variables and their interactions), and by sequentially reducing the model terms. We chose the best model by comparing the Akaike Information Criteria with correction for small sample sizes (AICc) and by selecting the model with the lowest AICc value (Bolker et al., 2008; Johnson and Omland, 2004).

\section{Results}

We walked a total of $22.4 \mathrm{~km}$ in the 112 transects performed over the four years. We recorded a total of 48 and 86 plant and pollinator species, respectively (full list of plant and pollinator species in Table A.1 - Appendix A). We recorded 233 plant-pollinator interactions between 29 flowering plant species and 45 bee species before the conservation actions (2011 - 2012), and 297 plantpollinator interactions between 41 flowering species and 56 bee species after the conservation actions (2013 - 2014). Plant species turnover between the two periods was lower than pollinator species turnover $(S=0.31$ and $S=0.56$, respectively).

\subsection{Network structure}

\subsubsection{Connectance}

Connectance levels were low in both the pre- $(C=0.066)$ and post-conservation action $(C=0.061)$ periods, but were comparable to values found for visitation networks of similar size (e.g. $0.04<C<$ 
0.05 in Memmott and Waser, 2002; $0.05<C<0.09$ in Forup and Memmott, 2005). Values of

295 connectance did not significantly differ from each other between the two periods (Table 1).

\section{Table 1}

298 Descriptors of the plant-pollinator visitation networks during the pre- and post-conservation 299 periods. Differences between connectance, specialization, evenness and modularity levels were 300 tested using the pre- vs. post- randomization procedure described in the text.

\begin{tabular}{|c|c|c|c|c|c|c|}
\hline & $\begin{array}{l}\text { Pre-conservation } \\
\text { actions } \\
(2011-2012)\end{array}$ & $\begin{array}{l}\text { Post-conservation } \\
\text { actions } \\
(2013-2014)\end{array}$ & $\Delta$ post - pre & $p$-value & LCI & UCI \\
\hline \multicolumn{7}{|l|}{ Network level } \\
\hline Connectance $(C)$ & 0.066 & 0.061 & -0.005 & ns & -0.006 & -0.001 \\
\hline Specialization $\left(H_{2}{ }^{\prime}\right)$ & 0.667 & 0.445 & -0.222 & $<0.025$ & -0.204 & -0.029 \\
\hline Interaction evenness $\left(E_{2}\right)$ & 0.525 & 0.589 & 0.064 & $<0.05$ & 0.012 & 0.061 \\
\hline Modularity $(M)$ & 0.613 & 0.559 & -0.054 & ns & -0.204 & -0.010 \\
\hline
\end{tabular}

Species level

Plant species

specialization $\left(d_{p}\right)$

$0.673 \pm 0.03$

$0.464 \pm 0.04$

$-0.209$

$<0.025$

$-0.180 \quad-0.033$

Pollinator species

specialization $\left(d_{i}{ }^{\prime}\right)$

$0.503 \pm 0.04$

$0.462 \pm 0.03$

$-0.041$

ns

$\begin{array}{ll}-0.128 & 0.014\end{array}$

Plant and pollinator species specialization indices are given as average values over all species \pm SE.

Lower (LCI) and upper (UCI) 95\% confidence intervals obtained after randomizations are reported

for each $\Delta$ value. $\mathrm{ns}=$ not significant.

\subsubsection{Specialization}

306 Specialization at the network level $\left(\mathrm{H}_{2}{ }^{\prime}\right)$ significantly decreased after the conservation actions 
$\left(H_{2}{ }^{\prime}\right.$ pre $=0.67$ and $H_{2}{ }^{\prime}$ post $=0.45, p<0.025$; Fig. 1, Table 1). Similarly, mean specialization at the

species level (average $d_{p}{ }^{\prime}$ over all species) decreased after the conservation actions in both plant

$\left(d_{p \text { pre }}{ }^{\prime}=0.68 \pm 0.03\right.$ and $d_{p}{ }^{\prime}$ post $\left.=0.46 \pm 0.04\right)$ and pollinator species $\left(d_{i p r e}{ }^{\prime}=0.50 \pm 0.04\right.$ and $d_{i p o s t}{ }^{\prime}=$

$0.46 \pm 0.03$ ), but only significantly so in plants (Table 1 ).

Fig. 1. Bipartite representation of plant-pollinator networks before and after the implementation of conservation actions. Lower bars represent plant species, while higher bars represent pollinator species (within each network, bar size is proportional to the number of links recorded for each species). Link width (grey lines that connect plant to pollinator species) is proportional to the number of observed interactions between plant and pollinator species. Dictamnus albus (P0; dark grey), and bee plants whose populations were reinforced during conservation actions (P27 Prunella laciniata, P29 - Veronica spicata, P57 - Cephalaria transsylvanica; light grey) are highlighted in the lower bars. Bee species that were favored by conservation actions (I28 - Bombus terrestris, I40 - Xylocopa violacea, I74 - Megachile circumcincta, I78 - Megachile centuncularis, I80 - Osmia bicornis; light grey) are highlighted in the higher bars. See Table A.1 in Appendix A for the complete list of plant and pollinator species. 


\section{Pre-conservation actions}

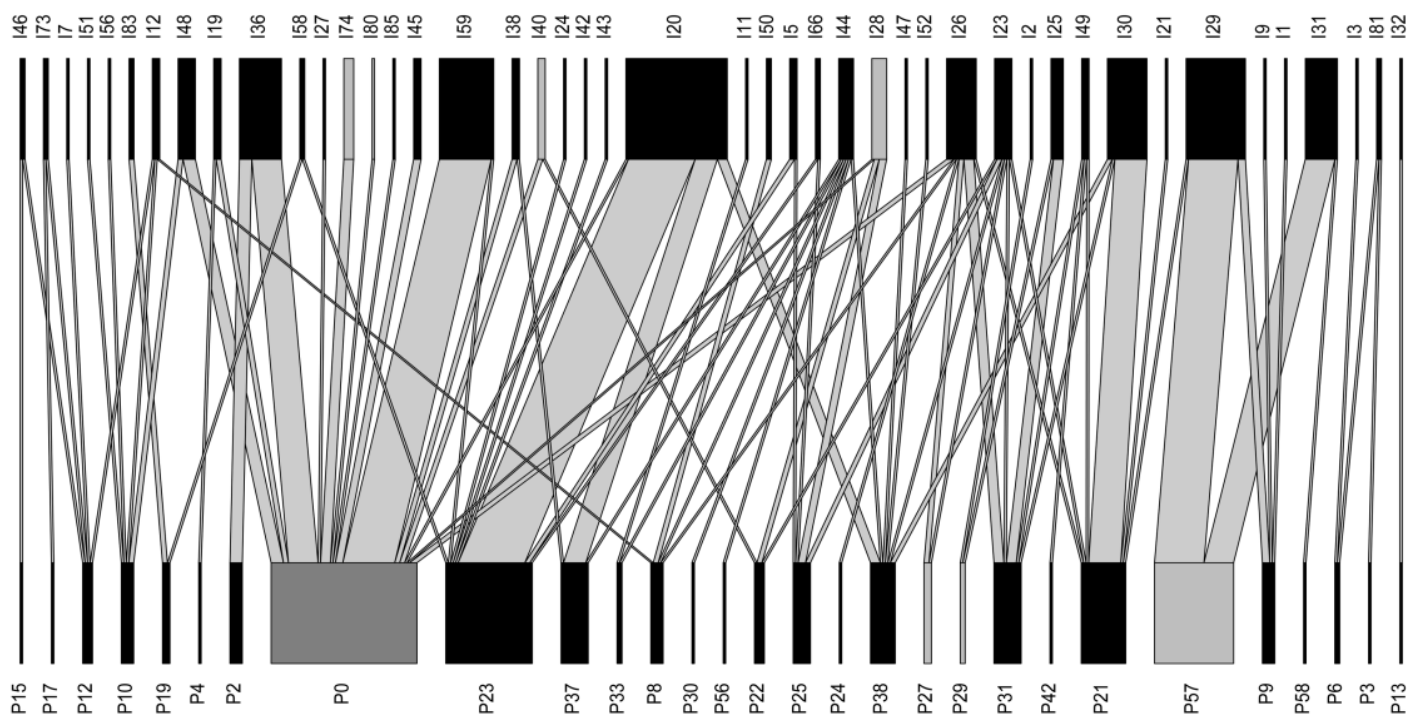

\section{Post-conservation actions}

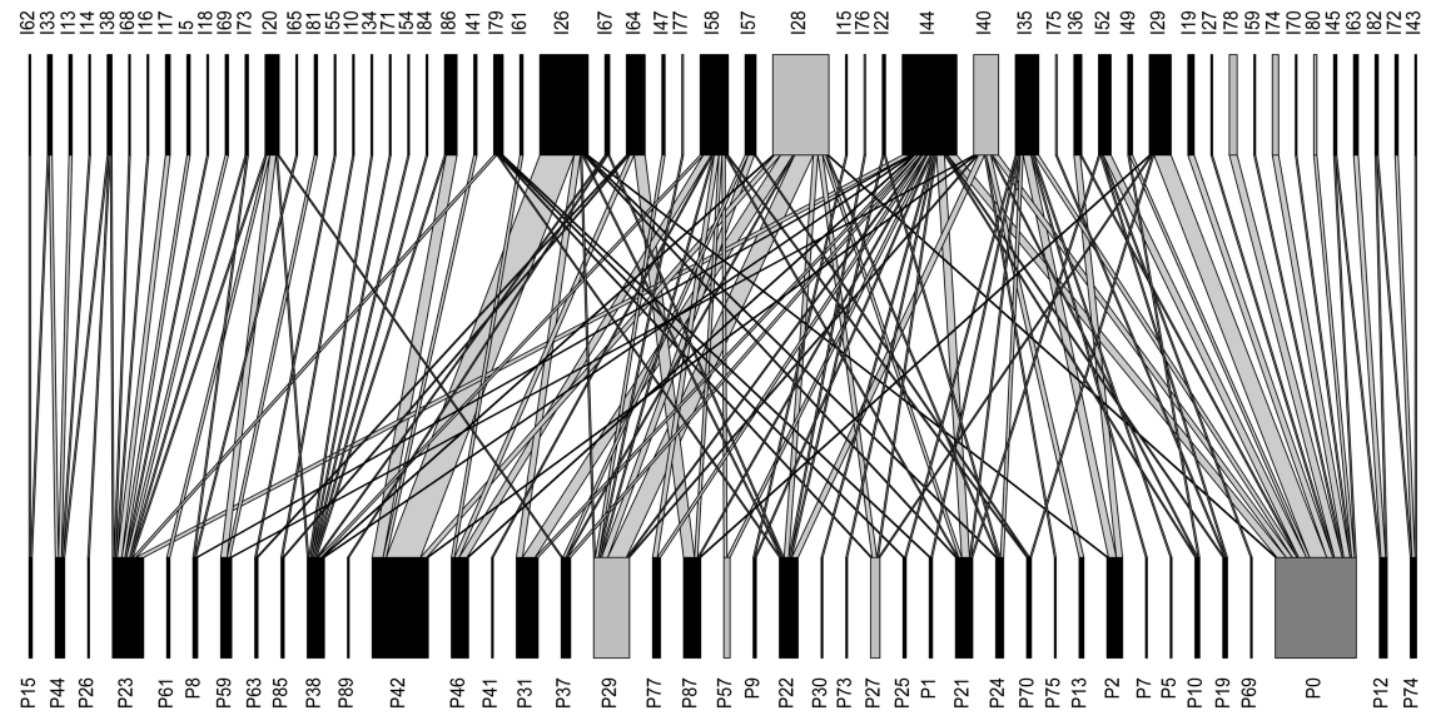

\subsubsection{Evenness}

Interaction evenness $\left(E_{2}\right)$ slightly but significantly increased from 0.53 to $0.59(p<0.05)$ after the

327 implementation of the conservation actions (Fig. 1, Table 1). 
Network modularity slightly decreased after the implementation of conservation actions, but not at a significant level (Table 1). We found 11 modules and 8 modules in the pre- and post-conservation action periods, respectively (species module composition is reported in Table A.2 - Appendix A). Modularity was significantly higher than expected from random permutations only in the postconservation action period ('curveball' permutations, pre-: $p=0.382$; post-: $p=0.001$ ).

335 The normalized mutual information index quantifying the correspondence between modules in the 336 two periods was low $(\mathrm{NMI}=0.36)$, and did not show significant similarity of module structure 337 between the post- and pre-conservation action periods ( $p=0.539$ for $\mathbf{A}$ matrices, tested using the 338 pre- vs. post- interaction randomization procedure). The alluvial diagram showed a significant 339 rearrangement among modules in the two periods, and highlighted that the module including $D$. 340 albus (module 1) was the most stable between them (Fig. 2).

342 Fig. 2. Alluvial diagram showing species rearrangement among blocks between the periods before 343 (Pre) and after (Post) the implementation of the conservation actions. Dictamnus albus is included 344 in module 1 in both periods. Full species module composition is reported in Table A.2 - Appendix 345 A 


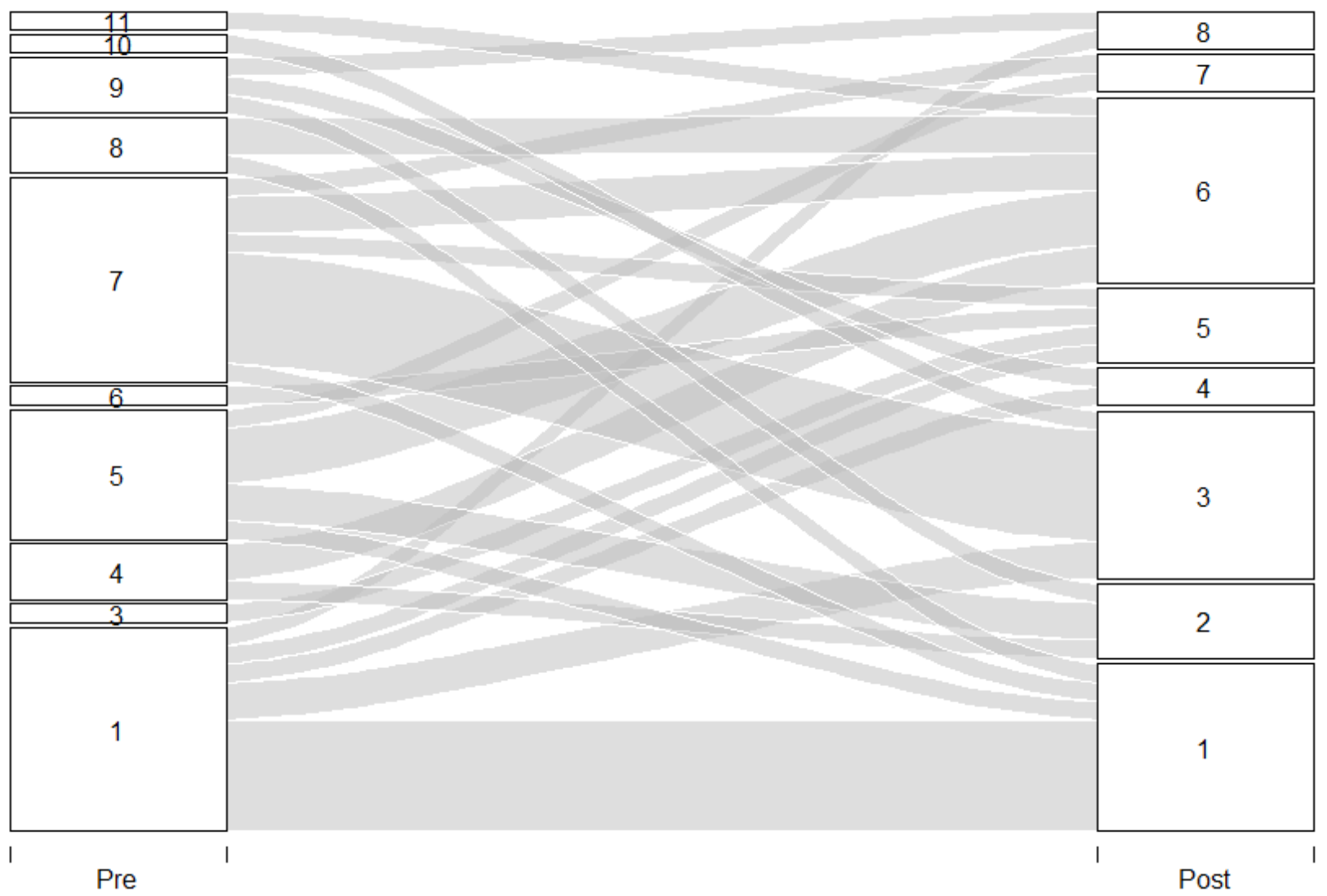

Regarding the role of single species within modules based on their $\mathrm{c}-\mathrm{z}$ scores, we found some differences in both plant and pollinator species between the two observation periods. The focal species D. albus was a module hub both before and after the implementation of conservation actions, while among bee plants Prunella laciniata became a module connector after the reinforcement of its population (Fig. 3). Concerning pollinators, $X$. violacea and B. terrestris became module connectors after the implementation of bee hotels and the reinforcement of their colonies, respectively (Fig. 3).

Fig. 3. Representation of the role of plant (grey dots) and pollinator (black dots) species in the preand post-conservation action periods, based on $\mathrm{c}-\mathrm{z}$ scores according to threshold values given by Olesen et al. (2007). A module hub is a highly connected species within its own module, while connectors are species that link several modules among them. Only species that were directly targeted by conservation actions and were either module hubs or connectors are highlighted for clarity (P0 - Dictamnus albus, P27 - Prunella laciniata; I28 - Bombus terrestris, I40 - Xylocopa violacea). 

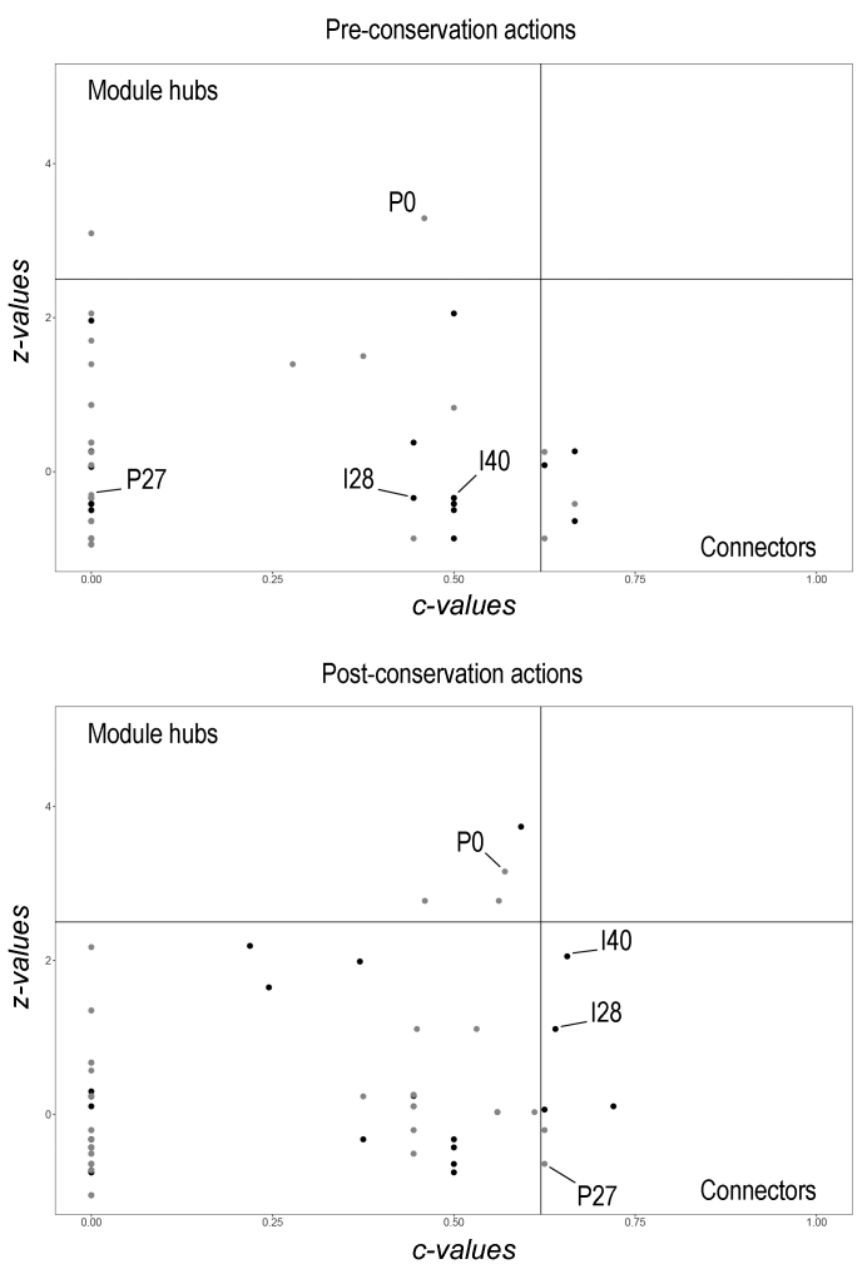

The PERMANOVA did not show significant effects of species phenology on the $\mathrm{c}-\mathrm{z}$ scores of plant nor pollinator species in any of the observed periods $\left(\mathrm{F}_{1,65}=0.061, p=0.526\right.$ before the conservation actions, and $\mathrm{F}_{1,94}=1.529, p=0.211$ after the conservation actions, based on 9999 permutations).

\section{2. $\quad$ Species targeted by conservation actions}

We here specifically consider plant and pollinator species that were targeted by conservation actions (Table A.1 in Appendix A) and that were observed in both periods.

373 Flowers of D. albus were visited 59 times by 14 bee species before the conservation actions, while 374 they were visited 52 times by 16 bee species after the conservation actions. The specialization index 375 of $D$. albus decreased after the conservation actions $\left(d_{\text {pre }}^{\prime}=0.75, d_{\text {post }}^{\prime}=0.60\right)$. The specialization 
index of pollinators visiting $D$. albus was low and comparable between the two observed periods $\left(d_{\text {pre }}^{\prime}=0.31 \pm 0.06, d_{\text {post }}^{\prime}=0.28 \pm 0.04\right)$.

Two bee plants ( $P$. laciniata and Veronica spicata) received more visits by a higher number of pollinator species after the conservation actions, while Cephalaria transsylvanica received a lower number of visits by the same number of pollinator species after the implementation of the conservation actions (Table 2). All three plant species showed a decreased specialization index in the second study period (Table 2).

\section{Table 2}

Flowering occurrence, number of visits received by pollinators, number of bee species observed, and specialization index $\left(d^{\prime}\right)$ in bee plants that flowered both before (Pre) and after (Post) the conservation actions. $x$ symbols indicate for each species the monthly presence before (Pre) and after (Post) the conservation actions. None of these species flowered in March, April or May.

\begin{tabular}{|c|c|c|c|c|c|c|c|c|}
\hline & $\begin{array}{l}\text { Conservation } \\
\text { actions }\end{array}$ & June & July & Aug & Sept & $\begin{array}{l}\text { Pollinator } \\
\text { visits }\end{array}$ & $\begin{array}{l}\text { Bee } \\
\text { species }\end{array}$ & $d$ 'plant \\
\hline \multirow{2}{*}{ Prunella laciniata } & Pre & $\mathrm{x}$ & & & & 3 & 2 & 0.45 \\
\hline & Post & $\mathrm{x}$ & $\mathrm{x}$ & & & 7 & 4 & 0.18 \\
\hline \multirow{2}{*}{ Veronica spicata } & Pre & $\mathrm{x}$ & $\mathrm{x}$ & $\mathrm{x}$ & $\mathrm{x}$ & 2 & 2 & 0.77 \\
\hline & Post & $\mathrm{x}$ & $\mathrm{x}$ & $\mathrm{x}$ & $\mathrm{x}$ & 32 & 10 & 0.46 \\
\hline \multirow{2}{*}{$\begin{array}{l}\text { Cephalaria } \\
\text { transylvanica }\end{array}$} & Pre & & & $\mathrm{x}$ & $\mathrm{x}$ & 32 & 2 & 0.92 \\
\hline & Post & & & $\mathrm{x}$ & $\mathrm{x}$ & 7 & 2 & 0.25 \\
\hline
\end{tabular}

All the pollinator species that were targeted by conservation actions were more abundant after their implementation. B. terrestris was the most abundant visitor both before and after the reinforcement of its local population (Table 3). Among the three solitary bee species that benefited from artificial nesting sites (Bortolotti et al., 2016), X. violacea showed a five-fold increase in visits, Osmia bicornis more than doubled its visits and Megachile spp. showed a three-fold increase of visits after the conservation actions (Table 3). B. terrestris and O. bicornis showed a similar decrease of 
specialization level in the second study period, while $X$. violacea and Megachile spp. showed a 397 similar increase in the specialization level (Table 3).

\section{Table 3}

400 Number of flower visits and specialization index of pollinator taxa that were targeted by 401 conservation actions.

\begin{tabular}{llllll}
\hline Pollinator taxon & Total visits & Visits pre & Visits post & $\boldsymbol{d}^{\prime}$ pre & $\boldsymbol{d}^{\prime}$ post \\
\hline Bombus terrestris & 42 & 6 & 36 & 0.58 & 0.42 \\
Xylocopa violacea & 19 & 3 & 16 & 0.27 & 0.41 \\
Osmia bicornis & 17 & 5 & 12 & 0.60 & 0.47 \\
Megachile spp. & 16 & 4 & 12 & 0.23 & 0.37 \\
\hline
\end{tabular}

Pre $=$ before the conservation actions

Post $=$ after the conservation actions

\subsection{Determinants of flower visits}

407 Plant species abundance and flowering phenology were the explanatory factors included in the best model predicting the total number of flower visits to the overall flowering community (Table 4).

409 The best fitting model was much better than the second best $(\triangle \mathrm{AICc}=6.85)$.

\section{Table 4}

411 Model selection results examining the influence of plant species abundance and phenology, and the 412 effect of conservation actions on flower visits by pollinators. The best model has the lowest AICc 413 (Akaike Information Criterion corrected for small sample size) value.

\begin{tabular}{llllllll}
\hline Response variable & Candidate models & (Intercept) & $d f$ & $\operatorname{logLik}$ & AICc & $\Delta$ AICc & W \\
\hline Flower visits & Rank, phen & -1.4330 & 11 & -418.700 & 860.6 & 0.00 & 0.943 \\
& Rank, treat, phen, phen*treat & -1.6120 & 15 & -417.615 & 867.4 & 6.85 & 0.031 \\
& Rank, treat, rank*treat, phen & -1.5100 & 15 & -417.833 & 867.9 & 7.28 & 0.025 \\
& $\begin{array}{l}\text { Rank, treat, rank*treat, phen, } \\
\text { phen*treat }\end{array}$ & -1.6160 & 18 & -417.253 & 873.7 & 13.11 & 0.001 \\
& Rank & -0.8253 & 6 & -432.234 & 876.8 & 16.24 & 0.000 \\
\hline
\end{tabular}




$\begin{array}{lcccccc}\text { Rank, treat, rank*treat } & -0.9921 & 10 & -430.807 & 882.6 & 22.01 & 0.000 \\ \text { Phen } & -1.0810 & 8 & -439.378 & 895.4 & 34.80 & 0.000 \\ \text { Treat, phen, phen*treat } & -1.4150 & 12 & -436.958 & 899.3 & 38.74 & 0.000 \\ & -0.2554 & 3 & -452.966 & 912.0 & 51.44 & 0.000\end{array}$

414

\section{Table 5}

Rank - plant species abundance (categorical variable), treat - occurrence of conservation actions (categorical), phen - plant species phenology (categorical). $d f$ indicates the model degrees of freedom (each model includes three degrees of freedom relative to the intercept, the residual variance and the random effect), $\triangle \mathrm{AICc}$ represents the difference of AICc values to the best model and $\mathrm{W}$ the AICc model weights (Akaike weight).

Flower visits increased following the increase of plant abundance (Table 5). All plant species that flowered for two or more months had a low and comparable positive effect on pollinator flower visits, with the exception of plant species that flowered for five months which highly increased flower visits (Table 5). Only two species flowered for five months (Lotus corniculatus and Taraxacum levigatum). Visits increased only for T. levigatum and were mainly related to one bee species (Lasioglossum puncticolle) that occurred in August 2013.

Results of the generalized linear mixed model (GLMM) for the effect of plant abundance and phenology on flower visits by pollinators.

\begin{tabular}{llllll}
\hline Response variable & Factors & Estimate & Std. Error & z-value & $\operatorname{Pr}(>|\mathbf{z}|)$ \\
\hline Flower visits & Fixed effects & & & & \\
& (Intercept) & -1.4332 & 0.3069 & -4.670 & $3.01 \mathrm{e}-06 * * *$ \\
& Rank2 & 0.9119 & 0.2926 & 3.117 & $0.00183 * *$ \\
& Rank3 & 2.2519 & 0.4549 & 4.950 & $7.41 \mathrm{e}-07 * * *$ \\
& Rank4 & 3.5813 & 0.7193 & 4.979 & $6.39 \mathrm{e}-07 * * *$ \\
& Phen2 & 1.1598 & 0.2850 & 4.069 & $4.72 \mathrm{e}-05 * * *$ \\
& Phen3 & 1.1077 & 0.5626 & 1.969 & $0.04897 *$ \\
& Phen4 & 1.5976 & 0.5626 & 1.930 & 0.05358. \\
\hline
\end{tabular}




$\begin{array}{cllll}\text { Phen5 } & 3.5936 & 0.8277 & 3.547 & 0.00039 \text { *** } \\ \text { Phen6 } & 1.4221 & 1.3228 & 1.075 & 0.28236 \\ \text { Random effect } & \text { Variance } & \text { St.Dev. } & & \\ \text { Plant species } & 1.923 & 1.387 & & \end{array}$

430

431

432

433

434

435

436

437

Rank - plant species abundance, from lowest (1 - intercept) to highest (4), Phen - number of months in which plant species were found in bloom $(1$ is the intercept). $*: p$-value $<0.05$; **: $p$ value $<0.01 ; p$-value $<0.001$

\section{Discussion}

We analyzed the structure of plant-pollinator networks before and after the implementation of conservation measures in a natural area. We found that species generalisation increased after interventions, especially for plants, while interactions were more evenly distributed. Only the postintervention network was significantly modular, and module composition was not congruent with that of the pre-conservation action period. Dictamnus albus, the focal plant of the conservation actions, was the most visited species during its flowering period and acted as an important hub within its module in both the pre- and post-conservation actions periods. Dictamnus albus displayed an increased generalisation level after the conservation measures. Bee plants whose populations were reinforced were generally more visited by bees and displayed an increased generalization level compared to the pre-existing situation. In their turn, bee species that were directly favored by conservation actions showed a marked increase of visits to local plants throughout the flowering season, but their generalisation levels responded heterogeneously.

\subsection{Limitations of the study}

The use of a low-impact sampling method, and the consequentially relatively low number of sampled pollinators and interactions, was dictated by the fact that the functionality of the study system, i.e. Dictamnus albus and its pollinators, is threatened by several factors and especially pollination limitation (Fisogni et al., 2016). Since the present study aimed at evaluating the effects 
of conservation measures specifically implemented to benefit both the local plant and pollinator communities (Bortolotti et al., 2016), an oversampling could have negatively affected the outcome of such actions and the effort made to obtain it. The use of a standardized methodology throughout the sampling seasons should guarantee the comparability of results over time. Moreover, we analyzed data using robust analyses and weighted metrics to overcome as much as possible any misrepresentation due to possible undersampling.

The conservation actions implemented aimed at supporting the pollinator fauna and increasing plant-pollinator interactions in the study site. Although it is difficult to demonstrate a direct relationship between the implemented actions and their effects on the local pollinator community, since the observed effects could also have been unexpected consequences of conservation measures (e.g. if the bee plants planted in the area attracted bees from the surroundings without actually increasing the local population), expected results were accomplished. Moreover, the amelioration of the local habitat quality, especially through the increase of floral resources, will probably facilitate the future survival of existing bee populations and promote the establishment of new bee nests in the study site (Carvell et al., 2017), with further benefits for the plant community.

\subsection{Network structure}

We observed a general increase of the generalisation level both in the entire network (through $\mathrm{H}_{2}$ ) and at the plant and pollinator species levels (through $d^{\prime}$ ) after the implementation of conservation actions, while evenness increased during the same period, indicating a more uniform repartition of visits among interaction partners. Despite these changes, connectance stayed approximately the same, thus suggesting that species overall interacted with a similar number of partners but in a more uniform way. This phenomenon could be interpreted in at least three, non-exclusive ways. First, the addition of new plants might provide an opportunity for generalist bees to sample more uniformly from the various plant species they can feed on. The conservation actions increased bee plants that are suitable for a large group of pollinators and that have a non-synchronized flowering phenology 
(Bortolotti et al., 2016), and explicitly aimed at providing sufficient resources throughout the year. Second, the addition of new plants might decrease competition among bee species by expanding dietary options, hence allowing some species to increase their generalisation level and, at the same time, increasing the generalisation level of conservation action-focal plants and nearby plants (Carvalho et al., 2014; Schleuning et al., 2012). Third, the addition of bee colonies of some of the most generalist species such as B. terrestris (Goulson and Darvill, 2004) might also increase the generalisation level of plants, since more plant species would thus be visited by the measuretargeted bee species. The significant increase of plant species generalisation after conservation management suggests that the local plant community should be less prone to negative effects connected to pollinator loss, because of increased functional redundancy (Memmott et al., 2004; Walker, 1995). Similarly, the increased generalisation of pollinators should buffer possible losses of flowering plants (Kaiser-Bunbury et al., 2010). In addition, we could expect positive effects of the increased plant and pollinator diversity, since high species diversity and the opportunism (i.e. high levels of generalism) of species interactions may further increase network resilience to phenological shifts or species loss (Bartomeus et al., 2013; Burkle and Alarcón, 2011).

The modules identified in the pre- and post-conservation action networks, restricted to species found in both periods, were not congruent. The lack of congruence in module composition indicates that significant interaction rewiring occurred between species belonging to different preconservation action modules. Temporal rewiring of interactions is generally high in natural communities, and is mainly driven by species phenology, abundance and behavior (Burkle and Alarcón, 2011; CaraDonna et al., 2017). It is not possible to determine whether the changes highlighted by our results are due to natural fluctuations or to the conservation actions, or to an interaction between the two. The augmentation of both pollinators and bee plants can have influenced the patterns of floral visitation and the consequent arrangement of their interactions. However, Dictamnus albus was included in the same module both before and after the conservation actions. Moreover, this module was the most stable of all modules with regard to species 
composition between the two periods. The analysis of c-z scores highlighted the species that became more central (i.e. connectors) and the species that were more important within their own module (i.e. hubs) following conservation actions. Two bee species (B. terrestris and X. violacea) and one plant species (P. laciniata) that were favored by conservation management became module connectors. Both B. terrestris and X. violacea are large-sized generalist species which could visit several flowering species for nectar or pollen (Goulson and Darvill, 2004; Vicidomini, 1995), thus connecting plants that may belong to different modules. Similarly, P. laciniata was visited by several solitary and social bee species that belonged to different modules. Dictamnus albus was a module hub in both periods, highlighting its primary role within its own module (Olesen et al., 2007). Connector species potentially play an important role for the resilience of the network, because their loss would increase modularity and therefore the fragmentation of the network (Dupont and Olesen, 2009; Olesen et al., 2007), while the loss of module hubs could lead to less densely connected modules (Memmott et al., 2004). The fact that D. albus was a module hub in a relatively stable module indicates that, during its short flowering period, it plays an important role not only by hosting several pollinator species, but also in ensuring the stability of the interactions that occur between those species included within its own module.

\subsection{Species targeted by conservation actions}

The increased generalisation in the overall network after the conservation actions was partly shaped by the higher generalisation observed in species directly targeted by conservation actions. Overall, these plants were visited more and by a higher number of pollinator species, highlighting their central role for the pollinator community as suitable foraging resources. This was particularly evident for P. laciniata, which became a module connector after the reinforcement of its population. Dictamnus albus, the focal plant of conservation strategy, was a key flowering species for the local community: it was the most abundant species during its blooming period (end of April - mid May) and attracted the majority (species and abundance) of pollinators (Fisogni et al., 2018, 2016). 
Following the interventions, its degree of specialization within the network decreased. At the same time, pollinators that visited $D$. albus were highly generalist both before and after the conservation actions. Despite possible negative effects on plant reproductive fitness (e.g. lower pollination efficiency, pollen discounting), the more diverse community of pollinators of $D$. albus should guarantee an "insurance" against a possible reduction in pollination efficiency by single groups of pollinators.

\subsection{Plant abundance and phenology}

More abundant plant species received more visits than less abundant ones. Increasing the number and abundance of bee plants in the study site therefore likely had a general positive effect by supporting the local pollinator community, or by attracting nearby pollinators. The importance of plant abundance and diversity in attracting pollinators has been highlighted in other studies

(Ghazoul, 2006; Knight, 2003; Norfolk et al., 2015). Moreover, the spatial clustering of bee plants (Bortolotti et al., 2016) may have increased their potential for attracting bees, whose vision relies more on patches of plants than on sparse single individuals (Giurfa and Leherer, 2001). However, since we cannot separate the effect of increased plant abundance from increased pollinator availability through the implementation of nesting sites and bumblebee colonies, it is likely that a higher availability of pollinators also contributed to the higher number of flower visits observed. Indeed, both conservation actions were carried out at the same time with the aim to increase the probability of having more flower visits.

We found that plant species that flowered for more than one month generally received more visits than species with a very short phenology. Longer plant phenologies can increase the probability of interaction with pollinators because of an increase in overlap with the flight period of a larger number of species (de Manincor et al., 2019; Olesen et al., 2011, 2008). Nevertheless, the increase in flower visits was comparable between species that flowered for two or more months, indicating a weak effect of flowering length on the number of visits received. The higher visits observed for $T$. 
levigatum were more likely linked to a sampling effect or to the pollinator phenology (e.g. our sampling occurred during the flight peak of L. puncticolle in that particular year) than to its longer (five months) flowering period.

\section{Conclusions}

In this work we used a network approach to analyze the effects of conservation actions carried out in a protected area for the safeguard of the rare plant $D$. albus and its bee pollinators. Network structure showed a general increase of more evenly distributed plant-pollinator interactions and higher species generalisation after conservation measures, with potential positive effects on the pollinator community. However, the analysis of modules showed a significant rewiring of plant pollinator interactions among species that were present in both periods. Dictamnus albus did not change its importance within the network after the implementation of conservation actions: during its relatively low flowering period it was visited by most bees sampled in the study area and it was an important hub connecting several species within its own module, likely playing an important role in its stability. Finally, the simultaneous habitat amelioration through bee plants reinforcement and increased pollinator availability through the placement of artificial nesting sites and bumblebee colonies led to increased flower visitation.

\section{Author contribution}

MG, AF and LB conceived the study. AF, NdM, GB, LB and MG performed field work. MQ identified bees. AF, NdM and FM analyzed data. AF wrote the article with input from FM and MG. All authors discussed and commented on the article.

\section{Acknowledgements}


582 We thank the Parco dei Gessi Bolognesi e Calanchi dell'Abbadessa for permitting field work. We 583 also thank the students that helped with bee collection and preparation throughout the study. This 584 work was performed within the Life+ Project PP-ICON (Plant-Pollinator CONservation approach: 585 a demonstrative proposal - LIFE09/NAT/IT000212) funded by the European Union. 


\section{References}

Aguilar, R., Ashworth, L., Galetto, L., Aizen, M.A., 2006. Plant reproductive susceptibility to habitat fragmentation: review and synthesis through a meta-analysis. Ecol. Lett. 9, 968-80. https://doi.org/10.1111/j.1461-0248.2006.00927.x

Astegiano, J., Altermatt, F., Massol, F., 2017. Disentangling the co-structure of multilayer interaction networks: degree distribution and module composition in two-layer bipartite networks. Sci. Rep. 7, 15465. https://doi.org/10.1038/s41598-017-15811-w

Astegiano, J., Massol, F., Vidal, M.M., Cheptou, P., Guimarães Jr, P.R., 2015. The robustness of plant-pollinator assemblages: linking plant interaction patterns and sensitivity to pollinator loss. PLoS One 10, e0117243. https://doi.org/10.1371/journal.pone.0117243

Bartomeus, I., Park, M., Gibbs, J., Danforth, B., Lakso, A.N., Winfree, R., 2013. Biodiversity ensures plant-pollinator phenological synchrony against climate change. Ecol. Lett. 16, 13311338. https://doi.org/10.1111/ele.12170

Bascompte, J., Jordano, P., 2007. Plant-animal mutualistic networks: the architecture of biodiversity. Annu. Rev. Ecol. Evol. Syst. 38, 567-593. https://doi.org/10.1146/annurev.ecolsys.38.091206.095818

Basilio, A.M., Medan, D., Torretta, J.P., Bartoloni, N.J., 2006. A year-long plant-pollinator network. Austral Ecol. 31, 975-983. https://doi.org/10.1111/j.1442-9993.2006.01666.x

Bates, A.J., Sadler, J.P., Fairbrass, A.J., Falk, S.J., Hale, J.D., Matthews, T.J., 2011. Changing bee and hoverfly pollinator assemblages along an urban-rural gradient. PLoS One 6, e23459. https://doi.org/10.1371/journal.pone.0023459

Bates, D., Mächler, M., Bolker, B.M., Walker, S.C., 2015. Fitting Linear Mixed-Effects Models Using lme4. J. Stat. Softw. 67, 1-48. https://doi.org/10.18637/jss.v067.i01

Biesmeijer, J.C., Roberts, S.P.M., Reemer, M., Ohlemüller, R., Edwards, M., Peeters, T., Schaffers, a P., Potts, S.G., Kleukers, R., Thomas, C.D., Settele, J., Kunin, W.E., 2006. Parallel declines in pollinators and insect-pollinated plants in Britain and the Netherlands. Science 313, 351354. https://doi.org/10.1126/science.1127863

Blüthgen, N., 2010. Why network analysis is often disconnected from community ecology: a critique and an ecologist' s guide. Basic Appl. Ecol. 11, 185-195. https://doi.org/10.1016/j.baae.2010.01.001

Blüthgen, N., Fründ, J., Vázquez, D.P., Menzel, F., 2008. What do interaction network metrics tell us about specialization and biological traits? Ecology 89, 3387-3399.

Blüthgen, N., Klein, A., 2011. Functional complementarity and specialisation: the role of biodiversity in plant - pollinator interactions. Basic Appl. Ecol. 12, 282-291. https://doi.org/10.1016/j.baae.2010.11.001

Blüthgen, Nico, Menzel, F., Blüthgen, Nils, 2006. Measuring specialization in species interaction networks. BMC Ecol. 6, 9. https://doi.org/10.1186/1472-6785-6-9

Blüthgen, Nico, Menzel, F., Hovestadt, T., Fiala, B., Blüthgen, Nils, 2007. Specialization, constraints, and conflicting interests in mutualistic networks. Curr. Biol. 17, 341-346. https://doi.org/10.1016/j.cub.2006.12.039 
Bojanowski, M., Edwards, R., 2016._alluvial: R Package for Creating Alluvial Diagrams_. R package version: 0.1-2, <URL: https://github.com/mbojan/alluvial>.

Bolker, B.M., Brooks, M.E., Clark, C.J., Geange, S.W., Poulsen, J.R., Stevens, M.H.H., White, J.S., 2008. Generalized linear mixed models: a practical guide for ecology and evolution. Trends Ecol. Evol. 24, 127-135. https://doi.org/10.1016/j.tree.2008.10.008

Bortolotti, L., Bogo, G., de Manincor, N., Fisogni, A., Galloni, M., 2016. Integrated conservation of bee pollinators of a rare plant in a protected area near Bologna, Italy. Conserv. Evid. 13, 5156.

Brosi, B.J., Briggs, H.M., 2013. Single pollinator species losses reduce floral fidelity and plant reproductive function. Proc. Natl. Acad. Sci. 6, 13044-13048. https://doi.org/10.1073/pnas.1307438110

Burkle, L.A., Alarcón, R., 2011. The future of plant-pollinator diversity: understanding interaction networks across time, space, and global change. Am. J. Bot. 98, 528-538. https://doi.org/10.3732/ajb.1000391

Canard, E., Mouquet, N., Marescot, L., Gaston, K.J., Gravel, D., Mouillot, D., 2012. Emergence of structural patterns in neutral trophic networks. PLoS One 7, e38295. https://doi.org/10.1371/journal.pone.0038295

CaraDonna, P.J., Petry, W.K., Brennan, R.M., Cunningham, J.L., Bronstein, J.L., Waser, N.M., Sanders, N., 2017. Interaction rewiring and the rapid turnover of plant - pollinator networks. Ecol. Lett. 20, 385-394. https://doi.org/10.1111/ele.12740

Carvalheiro, L., Barbosa, E.R.M., Memmott, J., 2008. Pollinator networks, alien species and the conservation of rare plants: Trinia glauca as a case study. J. Appl. Ecol. 45, 1419-1427. https://doi.org/10.1111/j.1365-2664.2008.01518.x

Carvalho, D., Presley, S., Santos, G., 2014. Niche overlap and network specialization of flowervisiting bees in an agricultural system. Neotrop. Entomol. 43, 489-499. https://doi.org/10.1007/s13744-014-0239-4

Carvell, C., Bourke, A.F.G., Dreier, S., Freeman, S.N., Hulmes, S., Jordan, W.C., Redhead, J.W., Sumner, S., Wang, J., Heard, M.S., 2017. Bumblebee family lineage survival is enhanced in high-quality landscapes. Nature 543, 547-549. https://doi.org/10.1038/nature21709

Chappuis, E., 2014. Dictamnus albus. The IUCN Red List of Threathened Species.

Csardi, G., Nepusz, T., 2006. The igraph software package for complex network research. InterJournal, Complex Syst. 1695.

Danon, L., Albert, D.-G., Duch, J., Arenas, A., 2005. Comparing community structure identification. J. Stat. Mech. P09008.

de Manincor, N., Hautekèete, N., Piquot, Y., Schatz, B., Vanappelghem, C., Massol, F., 2019. Does phenology explain plant-pollinator interactions at different latitudes? An assessment of its explanatory power in plant-hoverfly networks in French calcareous grasslands. https://doi.org/10.5281/zenodo.2542845

Deguines, N., Jono, C., Baude, M., Henry, M., Julliard, R., Fontaine, C., 2014. Large-scale trade-off between agricultural intensification and crop pollination services. Front. Ecol. Environ. 12, 212-217. https://doi.org/10.1890/130054 
Dormann, C.F., Gruber, B., Fruend, J., 2008. Introducing the bipartite package: analysing ecological networks. R news 8, 8-11.

Dunne, J.A., Williams, R.J., Martinez, N.D., 2002. Network structure and biodiversity loss in food webs: robustness increases with connectance. Ecol. Lett. 5, 558-567.

Dupont, Y.L., Olesen, J.M., 2009. Ecological modules and roles of species in heathland plant-insect flower visitor networks. J. Anim. Ecol. 78, 346-353. https://doi.org/10.1111/j.13652656.2008.01501.x

Elle, E., Elwell, S.L., Gielens, G.A., 2012. The use of pollination networks in conservation. Botany 90, 525-534. https://doi.org/10.1139/B11-111

Fisogni, A., Cristofolini, G., Rossi, M., Galloni, M., 2011. Pollinator directionality as a response to nectar gradient: promoting outcrossing while avoiding geitonogamy. Plant Biol. 13, 848-856. https://doi.org/10.1111/j.1438-8677.2011.00453.x

Fisogni, A., Quaranta, M., Grillenzoni, F.-V., Corvucci, F., de Manincor, N., Bogo, G., Bortolotti, L., Galloni, M., 2018. Pollen load diversity and foraging niche overlap in a pollinator community of the rare Dictamnus albus L. Arthropod. Plant. Interact. 12, 191-200. https://doi.org/10.1007/s11829-017-9581-x

Fisogni, A., Rossi, M., Sgolastra, F., Bortolotti, L., Bogo, G., de Manincor, N., Quaranta, M., Galloni, M., 2016. Seasonal and annual variations in the pollination efficiency of a pollinator community of Dictamnus albus L. Plant Biol. 18, 445-454. https://doi.org/10.1111/plb.12417

Fontaine, C., Collin, C.L., Dajoz, I., 2008. Generalist foraging of pollinators: diet expansion at high density. J. Ecol. 96, 1002-1010. https://doi.org/10.1111/j.1365-2745.2008.01405.x

Forup, M.L., Henson, K.S.E., Craze, P.G., Memmott, J., 2008. The restoration of ecological interactions: plant-pollinator networks on ancient and restored heathlands. J. Appl. Ecol. 45, 742-752. https://doi.org/10.1111/j.1365-2664.2007.01390.x

Forup, M.L., Memmott, J., 2005. The restoration of plant - pollinator interactions in hay meadows. Restor. Ecol. 13, 265-274.

Ghazoul, J., 2006. Floral diversity and the facilitation of pollination. J. Ecol. 94, 295-304. https://doi.org/10.1111/j.1365-2745.2006.01098.x

Gibson, R.H., Nelson, I.L., Hopkins, G.W., Hamlett, B.J., Memmott, J., 2006. Pollinator webs, plant communities and the conservation of rare plants: arable weeds as a case study. J. Appl. Ecol. 43, 246-257. https://doi.org/10.1111/j.1365-2664.2006.01130.x

Giurfa, M., Leherer, M., 2001. Honeybee vision and floral displays: from detection to close-up recognition, in: Chittka, L., Thompson, J. (Eds.), Cognitive Ecology of Pollination. Cambridge University Press, New York, pp. 61-82.

Goulson, D., Darvill, B., 2004. Niche overlap and diet breadth in bumblebees; are rare species more specialized in their choice of flowers? Apidologie 35, 55-63. https://doi.org/10.1051/apido

Goulson, D., Lye, G.C., Darvill, B., 2008. Decline and conservation of bumble bees. Annu. Rev. Entomol. 53, 191-208. https://doi.org/10.1146/annurev.ento.53.103106.093454

Guimerà, R., Amaral, L., 2005. Functional cartography of complex metabolic networks. Nature 433, 895-900. https://doi.org/10.1038/nature03286.1. 
Hallmann, C.A., Sorg, M., Jongejans, E., Siepel, H., Hofland, N., Schwan, H., Stenmans, W., Müller, A., Sumser, H., Hörren, T., Goulson, D., De Kroon, H., 2017. More than 75 percent decline over 27 years in total flying insect biomass in protected areas. PLoS One 12. https://doi.org/10.1371/journal.pone.0185809

Hicks, D.M., Ouvrard, P., Baldock, K.C.R., Baude, M., Goddard, M.A., Kunin, W.E., Mitschunas, N., Memmott, J., Morse, H., Nikolitsi, M., Osgathorpe, L.M., Potts, S.G., Robertson, K.M., Scott, A. V, Sinclair, F., Westbury, D.B., Stone, G.N., 2016. Food for pollinators: quantifying the nectar and pollen resources of urban flower meadows. PLoS One 11, e0158117. https://doi.org/10.1371/journal.pone.0158117

Johnson, J.B., Omland, K.S., 2004. Model selection in ecology and evolution. Trends Ecol. Evol. 19, 101-108. https://doi.org/10.1016/j.tree.2003.10.013

Kaiser-Bunbury, C.N., Blüthgen, N., 2015. Integrating network ecology with applied conservation: a synthesis and guide to implementation. AoB Plants 7, plv076. https://doi.org/10.1093/aobpla/plv076

Kaiser-Bunbury, C.N., Mougal, J., Whittington, A.E., Valentin, T., Gabriel, R., Olesen, J.M., Blüthgen, N., 2017. Ecosystem restoration strengthens pollination network resilience and function. Nature 542, 223-227. https://doi.org/10.1038/nature21071

Kaiser-Bunbury, C.N., Traveset, A., Hansen, D.M., 2010. Conservation and restoration of plantanimal mutualisms on oceanic islands. Perspect. Plant Ecol, Evol Syst. 12, 131-143. https://doi.org/10.1016/j.ppees.2009.10.002

Knight, T.M., 2003. Floral density , pollen limitation , and reproductive success in Trillium grandiflorum. Oecologia 442, 557-563. https://doi.org/10.1007/s00442-003-1371-8

Larson, D.L., Droege, S., Rabie, P.A., Larson, J.L., Devalez, J., Haar, M., Mcdermott-kubeczko, M., 2014. Using a network modularity analysis to inform management of a rare endemic plant in the northern Great Plains, USA. J. Appl. Ecol. 51, 1024-1032. https://doi.org/10.1111/13652664.12273

Memmott, J., Waser, N.M., 2002. Integration of alien plants into a native flower - pollinator visitation web. Proc. R. Soc. B Biol. Sci. 269, 2395-2399. https://doi.org/10.1098/rspb.2002.2174

Memmott, J., Waser, N.M., Price, M. V, 2004. Tolerance of pollination networks to species extinctions. Proc. R. Soc. B Biol. Sci. 271, 2605-2611. https://doi.org/10.1098/rspb.2004.2909

Michener, C.D., 2007. The Bees of the World, 2nd ed. The John Hopkins University Press, Baltimore.

Newman, M.E.J., 2006. Modularity and community structure in networks. Proc. Natl. Acad. Sci. $103,8577-8582$.

Norfolk, O., Eichhorn, M.P., Gilbert, F.S., 2015. Contrasting patterns of turnover between plants, pollinators and their interactions. Divers. Distrib. 21, 405-415. https://doi.org/10.1111/ddi.12295

Oksanen, J., Blanchet, F.G., Friendly, M., Kindt, R., Legendre, P., McGlinn, D., Minchin, P.R., O’Hara, R., Simpson, G.L., Solymos, P., Stevens, M.H.H., Szoecs, E., Wagner, H., 2019. vegan: Community Ecology Package. 
Olesen, J.M., Bascompte, J., Dupont, Y.L., Elberling, H., Rasmussen, C., Jordano, P., 2011. Missing and forbidden links in mutualistic networks. Proc. R. Soc. B 278, 725-732. https://doi.org/10.1098/rspb.2010.1371

Olesen, J.M., Bascompte, J., Dupont, Y.L., Jordano, P., 2007. The modularity of pollination networks. Proc. Natl. Acad. Sci. 104, 19891-19896.

Olesen, J.M., Bascompte, J., Elberling, H., Jordano, P., 2008. Temporal dynamics in a pollination network. Ecology 89, 1573-1582.

Ollerton, J., Erenler, H., Edwards, M., Crockett, R., 2014. Extinctions of aculeate pollinators in Britain and the role of large-scale agricultural changes. Science 346, 1360-1362.

Ollerton, J., Winfree, R., Tarrant, S., 2011. How many flowering plants are pollinated by animals? Oikos 120, 321-326. https://doi.org/10.1111/j.1600-0706.2010.18644.x

Poisot, T., Canard, E., Mouillot, D., Mouquet, N., Gravel, D., 2012. The dissimilarity of species interaction networks. Ecol. Lett. 15, 1353-1361. https://doi.org/10.1111/ele.12002

Potts, S.G., Biesmeijer, J.C., Kremen, C., Neumann, P., Schweiger, O., Kunin, W.E., 2010. Global pollinator declines: trends, impacts and drivers. Trends Ecol. Evol. 25, 345-353. https://doi.org/10.1016/j.tree.2010.01.007

Powney, G.D., Carvell, C., Edwards, M., Morris, R.K.A., Roy, H.E., Woodcock, B.A., Isaac, N.J.B., 2019. Widespread losses of pollinating insects in Britain. Nat. Commun. 10, 1018. https://doi.org/10.1038/s41467-019-08974-9

Schleuning, M., Fründ, J., Klein, A.-M., Abrahamczyk, S., Alarcón, R., Albrecht, M., Andersson, G.K.S., Bazarian, S., Böhning-Gaese, K., Bommarco, R., Dalsgaard, B., Dehling, D.M., Gotlieb, A., Hagen, M., Hickler, T., Holzschuh, A., Kaiser-Bunbury, C.N., Kreft, H., Morris, R.J., Sandel, B., Sutherland, W.J., Svenning, J.-C., Tscharntke, T., Watts, S., Weiner, C.N., Werner, M., Williams, N.M., Winqvist, C., Dormann, C.F., Blüthgen, N., 2012. Specialization of mutualistic interaction networks decreases toward tropical latitudes. Curr. Biol. 22, 19251931. https://doi.org/10.1016/j.cub.2012.08.015

Schnittler, M., Günther, K., 1999. Central European vascular plants requiring priority conservation measures-an analysis from national Red Lists and distribution maps. Biodivers. Conserv. 8, 891-925.

Strona, G., Nappo, D., Boccacci, F., Fattorini, S., San-miguel-ayanz, J., 2014. A fast and unbiased procedure to randomize ecological binary matrices with fixed row and column totals. Nat. Commun. 5, 4114. https://doi.org/10.1038/ncomms5114

Thomann, M., Imbert, E., Deveaux, C., Cheptou, P., 2013. Flowering plants under global pollinator decline. Trends Plants Sci. 18, 353-359. https://doi.org/10.1016/j.tplants.2013.04.002

Thomas, J.A., 2016. Butterfly communities under threat. Science 353, 216-218.

Tylianakis, J.M., Laliberté, E., Nielsen, A., 2010. Conservation of species interaction networks. Biol. Conserv. 143, 2270-2279. https://doi.org/10.1016/j.biocon.2009.12.004

Vicidomini, S., 1995. Biologia di Xylocopa violacea (L., 1758): specie di fiori visitate dalla femmina (Hymenoptera Apidae). Entomologica 29, 199-214.

Walker, B., 1995. Conserving biological diversity through ecosystem resilience. Conserv. Biol. 9, 
$788 \quad 747-752$.

789 